\title{
Current Perspectives in the Treatment of Locally Advanced Basal Cell Carcinoma
}

\author{
Neha Gupta \\ Emily S Ruiz
}

Department of Dermatology, Brigham and Women's Hospital, Harvard Medical School, Jamaica Plain, MA, USA
Correspondence: Emily S Ruiz Department of Dermatology, Brigham and Women's Hospital, Harvard Medical School, II 53 Centre Street, Suite 4], Jamaica Plain, MA, 02130, USA

Tel + | 617-983-4626

$\mathrm{Fax}+1$ 617-983-4504

Email esruiz@bwh.harvard.edu

\begin{abstract}
Basal cell carcinoma (BCC) is the most common cancer in Caucasians, and its incidence continues to rise. Generally, BCCs have good outcomes when diagnosed and treated early. However, $1-10 \%$ of patients will develop advanced disease due to either delays in accessing treatment or aggressive tumors that may be refractory to treatment. Locally advanced basal cell carcinomas (laBCCs) are large, aggressive, or recurrent tumors that have the potential to invade surrounding tissues including bone, cartilage, nerve, and muscle. Treatment requires a multi-disciplinary approach where different modalities including surgery, radiation therapy, Hedgehog Pathway Inhibitors, and immunotherapy can be considered.
\end{abstract}

Keywords: hedgehog pathway inhibitors, surgery, radiotherapy, immunotherapy, skin cancer

\section{Introduction}

Basal cell carcinoma (BCC) is the most common cancer in Caucasians, and its incidence continues to rise. ${ }^{1}$ When diagnosed and treated early, BCCs generally have good outcomes. However, $0.8-2 \%$ of patients will develop severe disease. ${ }^{2,3}$ Multiple expert multi-disciplinary groups have convened in order to define locally advanced BCCs (laBCCs). A multi-disciplinary group in the United Kingdom defined laBCCs as tumors with a primary tumor diameter greater than or equal to $2 \mathrm{~cm}$ (American Joint Committee on Cancer Staging 8 stage II or higher) in which surgery is contraindicated due to tumor or patient factors. Tumor factors include tumor size, location, number, subtype, and likelihood of successful treatment. Patient factors include age, performance status, opinions regarding treatment, comorbidities, genetic diseases, and morbidity of treatments. ${ }^{4}$ An Italian multidisciplinary group defined laBCCs not amenable to surgery or radiotherapy using the American Joint Committee on Cancer Staging 7 guidelines. These tumors include recurrent tumors after radiotherapy, tumors requiring surgery with unacceptable loss of function, T4 noneyelid tumors, and T3b-T4 eyelid tumors. T2 or T3 noneyelid tumors and $\mathrm{T} 3$ eyelid tumors can be included in this definition if they have any surgical or radiotherapy contraindications. ${ }^{5}$ A French multi-disciplinary group have also created a definition for LaBCCs. Their definition includes tumor factors, operability factors, and patient factors. ${ }^{6}$ In sum, these different groups define laBCCs as large, aggressive, or recurrent tumors that are deeply invasive and require extensive surgery. Treating laBCCs requires a multi-disciplinary approach where different treatment modalities including surgery, radiation therapy, Hedgehog Pathway Inhibitors (HHI), and immunotherapy, can be considered. This article examines the treatment options for laBCCs. 


\section{Surgery}

Surgical resection is typically performed with the intention of achieving clear histologic margins. There are two ways to assess margins: (1) Complete Circumferential Peripheral and Deep Margin Assessment (CCPDMA) and (2) Sectional Assessment. CCPDMA creates oblique sections of tissue allowing both lateral and deep margins to be evaluated simultaneously, thereby allowing $100 \%$ margin assessment. ${ }^{7}$ Surgical techniques that utilize CCPDMA include Mohs micrographic surgery, the Tubingen methods, en face sectioning, the Munich technique, and the Muffin technique. ${ }^{8,9}$ Sectional assessment creates "breadloaf" sections, which are cut at $2-3 \mathrm{~mm}$ intervals. This method creates skip areas that can be large enough for residual tumor to go undetected. ${ }^{7}$

According to the National Comprehensive Cancer Network (NCCN), high-risk tumors are located in a highrisk location and/or have a primary tumor diameter greater than or equal to $2 \mathrm{~cm}$, have poorly defined clinical borders, are recurrent, have high-risk pathology including perineural invasion, or occur in immunosuppressed patients or at a site previously treated with radiation therapy. NCCN recommends utilizing CCPDMA for definitive and curative treatment of these tumors due to lower recurrence rates. ${ }^{10}$ Wide local excisions with wider surgical margins (greater than $4 \mathrm{~mm}$ ) can serve as an alternative to CCPDMA. However, these procedures require a linear or delayed repair in order to ensure clear margins on pathology. If tumor margins are still positive, NCCN recommends resection utilizing the CCPDMA technique if feasible. ${ }^{10}$ In a randomized controlled trial comparing wide local excision to Mohs Micrographic surgery in the treatment of 612 high-risk facial BCCs, primary tumors treated with Mohs Micrographic surgery and wide local excision had a $4.4 \%$ and $12.2 \%$ 10-year recurrence rate, respectively. Recurrent tumors had a $3.9 \%$ and $13.5 \% 10$ year recurrence rate for MMS and WLE, respectively. ${ }^{11}$

The NCCN recommends multidisciplinary consultations for laBCCs and includes surgery as one potential therapeutic option. ${ }^{10}$ One study of 15 laBCCs resected surgically, including cranial resection, showed $80 \%$ disease-specific survival at 5 years. In these cases, surgeons were able to effectively control local disease and obtain negative margins without significant morbidity. ${ }^{12}$ However, laBCCs have the potential to infiltrate deeply into surrounding tissues on the head and neck including the eyes, nose, ears, cartilage, nerves and bone. Surgical removal of some laBCCs with clear margins can lead to severe disfigurement or loss of function of sensory organs, leading to extensive morbidity. ${ }^{2}$ Once surgery is deemed not feasible, curative radiotherapy or systemic therapy can be considered. ${ }^{10}$

\section{Radiation}

Radiotherapy can serve as an alternative option for BCC treatment. A retrospective study examining BCCs with a primary tumor diameter less than $4 \mathrm{~cm}$ treated with radiotherapy found a $2 \%$ and $4.2 \%$ recurrence at 2 and 5 years, respectively. ${ }^{13}$ Another 10 -year retrospective study of 175 BCCs treated with radiotherapy stratified recurrence rates by histological type. Low-risk nodular, superficial, and high-risk sclerosing subtypes had a 5-year recurrence rate of $8.2 \%, 26.1 \%$, and $27.7 \%$, respectively. ${ }^{14}$

Radiotherapy can also be utilized as a definitive treatment for laBCCs that cannot be resected or for patients who are not surgical candidates. ${ }^{10}$ One study of 61 laBCCs with a tumor diameter greater than $2 \mathrm{~cm}$ or deeply invasive disease had disease-specific survival and locoregional control as $76 \%$ and $86 \%$, respectively, at 4 years. Eight (13\%) of their tumors locally recurred at a median of 40.5 months after radiotherapy, of which 6 patients were able to undergo further treatment. ${ }^{15}$ A larger cohort of 388 laBCCs found the 10 -year recurrence rate to be $8.6 \%$ and $11.4 \%$ for T2 (tumor diameter $>2 \mathrm{~cm}$ and $\leq 5 \mathrm{~cm}$ ) and T3 tumors (tumor diameter $>5 \mathrm{~cm}$ ), respectively. This study found that thicker tumors with depth greater than or equal to $140 \mathrm{~mm}$ are more likely to recur. ${ }^{16}$ Another retrospective study of 88 head and neck Stage T4 carcinomas (bone and cartilage invasion), of which 41 were BCCs, found $53 \%$ and $49 \%$ local control at 5 and 10 years, respectively. When treated with salvage surgery after radiation, the local control was $90 \%$ and $85 \%$ at 5 and 10 years, respectively. They found that tumors that were previously untreated have no clinical evidence of bone or nerve invasion and invade a single deep structure (cartilage, skeletal muscle, bone or nerve) and have a higher likelihood of cure when treated with primary radiotherapy compared to other $\mathrm{T} 4$ tumors. ${ }^{17}$

Recurrent tumors may respond differently to radiotherapy. Tumor control was examined in a 10-year retrospective cohort study of 40 primary T2 tumors, 16 primary T3, and 9 primary T4. Tumor control was $90 \%, 94 \%$, and $100 \%$ for primary $\mathrm{T} 2, \mathrm{~T} 3$, and $\mathrm{T} 4$ tumors, respectively. However, this study found lower efficacy of radiotherapy in recurrent tumors with $89 \%, 33 \%$, and $67 \%$ tumor 
control by the last follow-up or death for recurrent T2, T3, and T4 tumors, respectively. ${ }^{18}$ On multivariate analysis, tumor control was also related to daily-dose fractionation and margin size. In addition, electron beam radiation technique improved over the cohort period. ${ }^{18}$ All of these factors could explain why recurrent $\mathrm{T} 3$ tumors had lower local control compared to recurrent T4 tumors.

Radiotherapy can also serve as treatment in the adjuvant setting for tumors that have extensive perineural invasion with negative margins or tumors with positive margins in which additional surgery is not feasible. ${ }^{10}$ Lin et al examined the local recurrence of 89 patients with $\mathrm{BCC}$ and perineural invasion on pathological examination. BCCs had a $91 \%$ relapse-free survival when treated with postoperative radiotherapy, with $75 \%$ of the recurrences occurring locally at a median of 44 months. ${ }^{19}$

Genetic conditions predisposing to skin cancer such as basal cell nevus syndrome and connective tissue diseases such as scleroderma are relative contraindications to radiotherapy due to an increased incidence of BCCs after treatment and increased risk of treatment-related toxicity, respectively. ${ }^{20,21}$ However, there have been cases reported of individuals with these conditions treated who were treated with radiotherapy and had no major complications at follow-up ${ }^{22,23}$ Patients with basal cell nevus syndrome or scleroderma should be evaluated clinically and have factors including tumor extent, age, and extent of underlying genetic disease be taken into account before deciding to use radiotherapy as a suitable treatment.

Patient functional status should also be considered. Radiation treatments require multiple visits, which may not be feasible for all patients. ${ }^{16}$ Also, additional courses of radiation may not be feasible in previously irradiated fields. ${ }^{24}$

Additional surgery after radiation might not be feasible due to wound healing complications that are frequently seen in irradiated tissue. ${ }^{25}$ Radiotherapy alters levels of transforming growth factor-beta, leading to fibrotic and hypovascular tissue, and contributing to chronic radiation damage that can affect surgical wound healing. ${ }^{26}$ Other adverse events include radiation-related skin toxicity, potential changes to underlying structures, alopecia, cartilage necrosis, and skin pigment changes. ${ }^{24}$

Radiotherapy can serve as a viable non-invasive alternative treatment option for laBCCs with a 10 -year recurrence of $8.6 \%$ and $11.4 \%$ for $\mathrm{T} 2$ and $\mathrm{T} 3$ tumors, respectively. ${ }^{16}$ Radiotherapy can even be utilized in the adjuvant setting for tumors that have positive margins or negative margins with high-risk features, such as perineural invasion, with a $91 \%$ relapse-free survival. ${ }^{19}$ However, it is important to note that recurrent tumors and radiation technique can provide poor control for $\mathrm{T} 2$ (89\% recurrent vs $90 \%$ primary), T3 (33\% recurrent vs $94 \%$ primary), and $\mathrm{T} 4$ (67\% recurrent vs $100 \%$ primary) tumors. $^{18}$

\section{Hedgehog Pathway Inhibitors}

Approximately $90 \%$ of sporadic BCCs have mutations in PTCH1, and $10 \%$ have mutations in SMO or downstream effectors, allowing intrinsic activation of sonic hedgehog pathway. ${ }^{27-29}$ PTCH1 is a transmembrane receptor that inhibits smoothened (SMO), an activator of the sonic hedgehog pathway. The hedgehog ligand binds to PTCH1, relieving inhibition on SMO, thereby allowing SMO to activate transcription factors GLI1, GLI2, and GLI3 promoting gene expression and tumorigenesis. ${ }^{30}$ HHIs/SMO inhibitors bind to and inhibit SMO, preventing constitutive activation of the pathway from a PTCH mutation (Figure 1).

HHIs are the first-line systemic treatment for locally advanced BCCs that have recurred following surgery or for patients who are not candidates for surgery or radiation. ${ }^{31,32}$ Surgical contraindications include recurrent tumors unlikely to achieve a cure after having been treated with two or more surgical procedures, the presence of substantial morbidity and deformity including loss of organ function, or patients who are not surgical candidates. ${ }^{33}$ Patients are eligible for HHI therapy if they have contraindications to radiotherapy including prior radiation in the area or general contraindications to radiotherapy as mentioned in the prior section. ${ }^{33}$

Vismodegib was the first HHI approved by the United States Food and Drug Administration (FDA) in January 2012. ${ }^{31}$ The Phase II study ERIVANCE (NCT00833417) examined 71 laBccs, and found that $60.3 \%$ of patients had an objective response, of which 18 patients had a decrease greater than $30 \%$ in the lesion, and 20 patients had a complete response. ${ }^{33}$ In the STEVIE (NCT01367665) trial, which included 1119 laBCCs, 69\% of patients with laBCC had a partial response, while 33\% had a complete response. ${ }^{34}$ In July 2015, the FDA approved a second HHI, sonidegib, for laBCCs not amenable to curative surgery or radiotherapy. ${ }^{32}$ In the BOLT study (NCT0132705), which evaluated two doses of sonidegib in 194 laBCCs, $56 \%$ and $46 \%$ of patients had an objective response in the $200 \mathrm{mg}$ and $800 \mathrm{mg}$ cohort, 
A

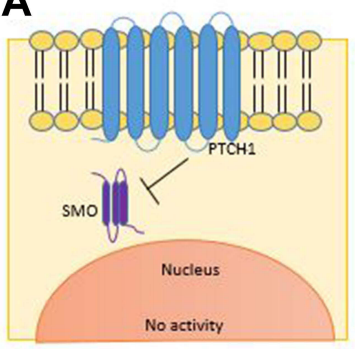

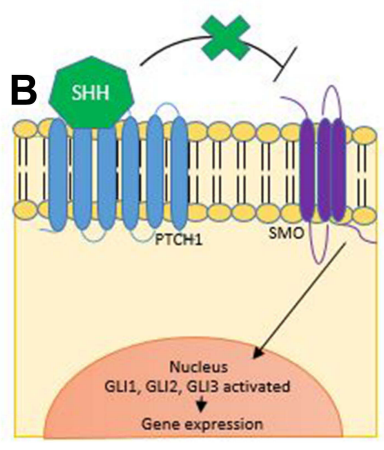

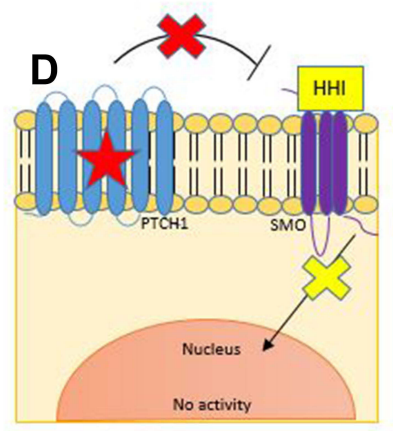

Figure I (A) PTCHI inhibits SMO activity, suppressing gene expression. (B) The sonic hedgehog ligand binds to PTCHI, relieving the inhibition of SMO, resulting in the activation of transcription factors GLII, GLI2, and GLI3, allowing gene expression. (C) In BCCs, mutations in PTCHI prevents its inhibition of SMO, allowing constitutive activation of the hedgehog pathway. Mutations in SMO render the SMO protein immune to PTCHI's inhibitory effects allowing constitutive pathway activity. (D) Hedgehog Pathway inhibitors bind to and inhibit SMO, preventing downstream activation of the pathway.

Abbreviations: $\mathrm{SHH}$, sonic hedgehog ligand; $\mathrm{HHI}$, hedgehog pathway inhibitor.

respectively. Only $5 \%$ and $2 \%$ of patients achieved a complete response in the $200 \mathrm{mg}$ and $800 \mathrm{mg}$ cohorts, respectively. ${ }^{35} \mathrm{~A}$ meta-analysis of $\mathrm{HHI}$ therapy compared the efficacy of vismodegib and sonidegib and showed similar overall response rates for vismodegib (69\%) and sonidegib (57\%). However, there was difference in complete response rates (31\% vismodegib vs 3\% sonidegib, $\mathrm{p}<0.0001) .{ }^{36}$ Of note, vismodegib is approved for metastatic $\mathrm{BCC}$; however, sonidegib did not receive that indication due to significantly lower response rates in that cohort compared to vismodegib. ${ }^{31,32,36}$

Neoadjuvant administration of HHIs can reduce tumor size and the morbidity of the initially planned surgery, facilitating surgical resection. The phase II trial VISMONEO (NCT02667574) treated 55 patients who had inoperable tumors or tumors in which surgery would cause significant morbidity either functionally or aesthetically with vismodegib $150 \mathrm{mg}$ daily. Vismodegib was discontinued once tumors achieved a best observed response, defined as no change in tumor size for at least 2 evaluations after the initial size reduction. After a median treatment duration of 6 months, $80 \%$ of patients' tumors shrunk, with a mean two-thirds size reduction, allowing them to undergo a less severe surgery. Fortynine percent of patients achieved a complete clinical response without any surgical treatment. ${ }^{37}$ However, of the 44 patients that had a successful down-staging, 16 $(36 \%)$ of the patients had a recurrence within three years of follow-up with two disease-specific deaths (DSDs). The Phase IV trial VISORB (NCT02436408) examined the effect of neoadjuvant vismodegib on preserving visual function in 35 globe- and lacrimal drainage system- threatening periocular BCCs. Vismodegib was taken for 12 months, until disease progression or until intolerable toxicity, at which point surgery was offered. Tumors were on average $44 \%, 22 \%$, and $20 \%$ of baseline size at 3,6 , and 12 months, respectively, with tumor maximum response at 6 months according to MRI/CT measurements. About $56 \%$ and $10 \%$ of patients achieved a complete and partial response, respectively. Of the 27 patients who chose to undergo surgery after vismodegib, $67 \%$ had no evidence of histologic disease, $22 \%$ had residual disease present but were able to obtain clear margins, and $11 \%$ had microscopic disease present with positive microscopic margins. After two years of follow-up, two patients developed a local recurrence. All patients maintained successful visual function. ${ }^{38}$ While the Vismoneo and VISORB trials have shown effective tumor shrinkage that could aid in reducing morbidity of surgery, more data is needed on the effect of neoadjuvant vismodegib on long-term survival.

A limitation to HHI therapy is the side effect profile, which is very common and often severe, but not life threatening. In the STEVIE trial, 98\% of patients on vismodegib experienced at least one adverse event, and 31\% of patients had adverse events that led to treatment discontinuation. About $35 \%$ and $4.5 \%$ of patients experienced a Grade 3 or 4 adverse event, respectively. ${ }^{34}$ In the BOLT trial, $89 \%$ of patients taking sonidegib $200 \mathrm{mg}$ experienced at least one adverse event, and 30\% discontinued treatment due an adverse event. Thirty-two percent of patients receiving $200 \mathrm{mg}$ and $43 \%$ of patients receiving $800 \mathrm{mg}$ of sonidegib experienced a grade 3-4 adverse event. ${ }^{35}$ In a meta-analysis of HHI therapy, the three most common side effects of vismodegib and sonidegib were muscle 
spasms (67\%), dysgeusia (54\%), and alopecia (58\%), and were significantly associated with HHI therapy ( $\mathrm{p}<$ $0.001) .{ }^{25}$ More than $25 \%$ of patients stopped treatment due to toxicity and recovered except for those with persistent alopecia. ${ }^{36}$ It is important to note that dose interruptions in both vismodegib and sonidegib $200 \mathrm{mg}$ and $800 \mathrm{mg}$ still had clinically meaningful responses. ${ }^{33,39}$ Another limitation to HHI therapy is that at around one year of continuous treatment, $8 \%$ of $1 \mathrm{aBCC}$ will develop secondary resistance through acquired mutations in SMO and PTCH1 that render the tumor no longer responsive. $^{40,41}$

Itraconazole, an antifungal agent, has activity in the hedgehog pathway by preventing activated SMO from localizing to the cilia, acting on a site distinct from vismodegib. Using mice models, Kim et al were able to show that itraconazole inhibits vismodegib-resistant SMO, acting as a partial antagonist and resulting in $92 \%$ growth inhibition. ${ }^{42}$ When combined with arsenic trioxide, there was a complete inhibition of tumor growth and $48 \%$ tumor regression. This combination had activity against all of the known drug-resistant SMO mutations and in GLI2 overexpression. ${ }^{42}$ An open-label Phase II clinical trial (NCT01108094) of 90 BCCs treated with itraconazole reported a $24 \%$ reduction in tumor size in vismodegib-naïve patients. No patient achieved a complete response. ${ }^{43}$ There is a case reported of a laBCC that achieved a complete response with itraconazole in combination with tumor debulking and topical calcipotriene mixed with 5 -fluorouracil. ${ }^{44}$ Side effects to itraconazole are generally mild and resolved on drug discontinuation. ${ }^{43}$

\section{Immune Checkpoint Inhibitors}

Programmed death 1 (PD-1) regulates the body's immune response in inflammatory reactions, chronic infections, or malignancy when $\mathrm{T}$ cells have experienced high levels of stimulation. When bound to its ligand PD-L1, PD-1 prevents phosphorylation of key $\mathrm{T}$ cell receptor signaling intermediates, preventing $\mathrm{T}$ cell receptor signaling and reducing $\mathrm{T}$ cell activation. It also inhibits $\mathrm{T}$ cell proliferation and survival by preventing the release of interferon- $\gamma$, tumor necrosis factor- $\alpha$, and IL-2 production. ${ }^{45}$ PD-1 inhibitors inhibit PD-1 binding, thereby restoring the body's antitumor immune response, allowing $\mathrm{T}$ cells to recognize the tumor, and leading to disease stabilization or even tumor regression (Figure 2). ${ }^{46}$

PD-L1 binding also induces the conversion of naïve $\mathrm{T}$ cells to T-regulatory cells, contributing to the body's reduced immune response. ${ }^{47}$ PD-L1 blockade has been shown to reverse the suppressed $\mathrm{T}$ cell response caused by T-regulatory cells (Figure 2) ${ }^{48}$

CD80 is a key molecule in the CTLA-4 pathway, which is similar to the PD-1 pathway, and influences $\mathrm{T}$ cell response. When bound to CD28, CD80 leads to the production of IL-2, promoting T cell survival, proliferation, and differentiation. However, when CD80 binds to PD-L1, the PD1:PDL-1 interaction is inhibited by $80 \%$, allowing up-regulation and survival of T cells. ${ }^{49}$

BCCs can express PD-1 and inherently dampen the body's immune response to the tumor. ${ }^{50}$ Interestingly, previously treated BCCs with surgery, radiotherapy, systemic chemotherapy, or topical chemotherapy have a higher PD-1 staining intensity. ${ }^{50}$ However, response rate to therapy has not been shown to correlate with tumor mutational burden or PD-1 staining, so these features are not used to determine treatment eligibility. ${ }^{51}$

Cemiplimab-rwlc, a PD-1 antibody, was approved by the FDA in 2021 for patients with laBCC previously treated with HHIs or for whom HHI use is not appropriate. $^{52}$ An open-label, phase II trial of 84 laBCCs (NCT03132636) that failed HHIs and were treated with cemiplimab (ie cemiplimab was used as a second-line treatment) found an objective response of $31 \%$ and a complete response of $6 \%$. The median time of progression-free survival was 19 months. ${ }^{51}$ There is also a case reported describing the complete response of two $4 \mathrm{~cm}$ BCCs in one patient treated with 1 year of cemiplimab with no adverse events noted. Biopsies following therapy of both sites showed scar and no evidence of residual tumor. ${ }^{53}$ With the recent FDA approval, cemiplimab is used for laBCCs as a second-line systemic therapy following $\mathrm{HHI}$ or as a first-line treatment for patients deemed not eligible for HHIs.

While other PD-1 inhibitors are not approved for laBCCs, there are reports showing efficacy. An openlabel study of 16 advanced BCCs (NCT02690948) reported a $44 \%$ response rate with pembrolizumab monotherapy and $29 \%$ response rate with combination pembrolizumab and vismodegib. ${ }^{54}$

PD-1 inhibitors have not been formally studied in the neoadjuvant setting for laBCCs. However, there is a case series of two patients with unresectable BCCs who received neo-adjuvant PD-1 inhibitors. One patient with a $21 \mathrm{~cm}$ BCC treated with nivolumab no longer needed surgery after achieving complete remission. The other patient had three unresectable lesions treated with 

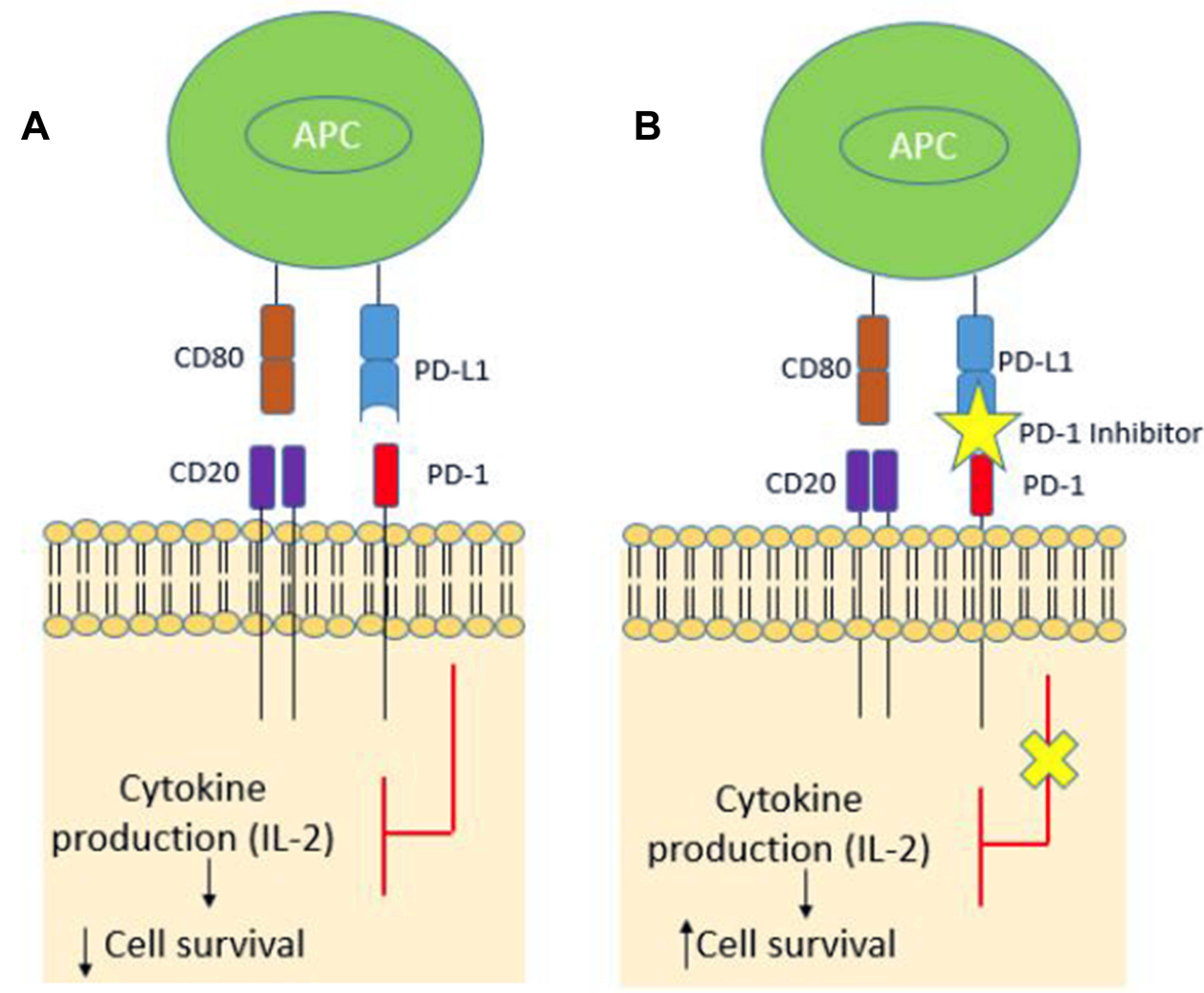

Figure 2 (A) PD-I and PD-LI binding inhibits cytokine production, causing decreased cell survival. (B) PD-I inhibitors prevent the binding between PD-I and PD-LI, allowing activation of this pathway and induction of T-cells that recognize and target tumor cells.

Abbreviation: APC, antigen presenting cell.

pembrolizumab and achieved a partial response, reducing the size of her tumors to that considered resectable. ${ }^{55}$

PD-1 inhibitors are better tolerated than HHIs with fatigue serving as a main complaint for patients. ${ }^{54}$ In the Phase II clinical trial for cemiplimab, common side effects included fatigue (26\% Grade 1-2 and 4\% Grade 3), diarrhea $(24 \%)$, and pruritus $(21 \%) .{ }^{51}$ Treatment discontinuation from intolerable toxicity is only $5-8 \%$ compared to chemotherapy (6\%), dacarbazine (12\%), ipilimumab (9$15 \%$ ), and HHI therapy (28\%). ${ }^{56,57}$ Treatment related adverse events that led to discontinuation of treatment in cemiplimab included adrenal insufficiency, asthenia, colitis, enterocolitis, hypophysitis, immune-mediated hepatitis, acute kidney injury, renal failure, and immune-related hypothyroidism. ${ }^{51}$ However, PD-1 inhibitors, similar to any immune checkpoint inhibitor, have a unique class of adverse events similar to autoimmune-like toxicity known as immune related adverse events. PD-1 inhibitors increase the body's immune response, inducing infiltration of immune cells into normal tissue, including the skin, colon, liver, kidneys, eyes, endocrine tissues, and central nervous system, causing immune related adverse events. ${ }^{56}$ Rash (14\%), hypothyroidism (5\%), pneumonitis (3\%), and colitis $(2 \%)$ are common immune related adverse events. $^{58}$

\section{Conclusion}

LaBCC treatment is complex and often requires a multidisciplinary approach. First-line treatment is surgical resection with negative margins, but this is not always feasible. LaBCCs have the potential to invade into surrounding tissues that may require extensive surgeries that can create significant morbidity and reduced quality of life for patients or be inoperable. Radiation and systemic therapy can be used as alternative treatments or in combination with surgery. Systemic therapy is generally used when surgery and radiation are no longer an option. HHIs are first-line systemic therapy, and PD-1 inhibitors are second-line systemic therapies; however, cemiplimab can be used in first-line for patients not eligible for HHIs. 


\section{Disclosure}

Dr Emily S Ruiz reports consulting, co-investigator and/ or principal investigator from Regeneron, Sanofi, Merck, and Checkpoint Therapeutics, outside the submitted work. She is also a board member for Checkpoint Therapeutics. The authors report no other conflicts of interest in this work.

\section{References}

1. Cameron MC, Lee E, Hibler BP, et al. Basal cell carcinoma: epidemiology; pathophysiology; clinical and histological subtypes; and disease associations. J Am Acad Dermatol. 2019;80(2):303-317. doi:10.1016/j.jaad.2018.03.060

2. Goldenberg G, Karagiannis T, Palmer JB, et al. Incidence and prevalence of basal cell carcinoma (BCC) and locally advanced BCC (LABCC) in a large commercially insured population in the United States: a retrospective cohort study. $J$ Am Acad Dermatol. 2016;75 (5):957-966.e2. doi:10.1016/j.jaad.2016.06.020

3. Dreier J, Cheng PF, Alleman IB, et al. Basal cell carcinomas in a tertiary referral centre: a systematic analysis. $\mathrm{Br} J$ Dermatol. 2014;171(5):1066-1072. doi:10.1111/bjd.13217

4. Lear JT, Corner C, Dziewulski P, et al. Challenges and new horizons in the management of advanced basal cell carcinoma: a UK perspective. Br J Cancer. 2014;111(8):1476-1481. doi:10.1038/bjc. 2014.270

5. Peris K, Licitra L, Ascierto PA, et al. Identifying locally advanced basal cell carcinoma eligible for treatment with vismodegib: an expert panel consensus. Future Oncol. 2015;11:703-712. doi:10. 2217/fon.14.281

6. Amici JM, Battistella M, Beylot-Barry M, et al. Defining and recognising locally advanced basal cell carcinoma. Eur J Dermatol. 2015;25(6):586-594. doi:10.1684/ejd.2015.2641

7. Abide JM, Nahai F, Bennett RG. The meaning of surgical margins. Plast Reconstr Surg. 1984;73(3):492-497. doi:10.1097/00006534198403000-00030

8. Danesh MJ, Menge TD, Helliwell L, Mahalingam M, Waldman A. Adherence to the national comprehensive cancer network criteria of complete circumferential peripheral and deep margin assessment in treatment of high-risk basal and squamous cell carcinoma. Dermatol Surg. 2020;46(12):1473-1480. doi:10.1097/DSS.000000 0000002354

9. Möhrle M, Breuninger H. Die Muffin-Technik - eine Alternative zur Mohs' Chirurgie. J Dtsch Dermatol Ges. 2006;4(12):1080-1084. doi:10.1111/j.1610-0387.2006.06152.x

10. Schmults C, Blitzblau R, Alam M, et al. NCCN guidelines version 1.2022 basal cell skin cancer. Available from: https://www.ncen.org/ guidelines/guidelines-detail. Accessed July 22, 2021.

11. van Loo E, Mosterd K, Krekels GAM, et al. Surgical excision versus Mohs' micrographic surgery for basal cell carcinoma of the face: a randomised clinical trial with 10 year follow-up. Eur $J$ Cancer 2014;50(17):3011-3020. doi:10.1016/j.ejca.2014.08.018

12. Backous DD, DeMonte F, El-Naggar A, Wolf P, Weber RS. Craniofacial resection for nonmelanoma skin cancer of the head and neck. Laryngoscope. 2005;115(6):931-937. doi:10.1097/01. MLG.0000163766.66223.97

13. Cognetta AB, Howard BM, Heaton HP, Stoddard ER, Hong HG, Green WH. Superficial x-ray in the treatment of basal and squamous cell carcinomas: a viable option in select patients. $J$ Am Acad Dermatol. 2012;67(6):1235-1241. doi:10.1016/j.jaad.2012.06.001

14. Zagrodnik B, Kempf W, Seifert B, et al. Superficial radiotherapy for patients with basal cell carcinoma. Cancer. 2003;98(12):2708-2714. doi:10.1002/cncr.11798
15. Kwan W, Wilson D, Moravan V. Radiotherapy for locally advanced basal cell and squamous cell carcinomas of the skin. Int $J$ Radiat Oncol. 2004;60(2):406-411. doi:10.1016/j.ijrobp.2004.03.006

16. Schulte KW, Lippold A, Auras C, et al. Soft x-ray therapy for cutaneous basal cell and squamous cell carcinomas. $J$ Am Acad Dermatol. 2005;53(6):993-1001. doi:10.1016/j.jaad.2005.07.045

17. Al-Othman MO, Mendenhall WM, Amdur RJ. Radiotherapy alone for clinical T4 skin carcinoma of the head and neck with surgery reserved for salvage. Am J Otolaryngol. 2001;22(6):387-390. doi:10. 1053/ajot.2001.28083

18. Locke J, Karimpour S, Young G, Lockett MA, Perez CA. Radiotherapy for epithelial skin cancer. Int J Radiat Oncol. 2001;51 (3):748-755. doi:10.1016/S0360-3016(01)01656-X

19. Lin C, Tripcony L, Keller J, et al. Perineural infiltration of cutaneous squamous cell carcinoma and basal cell carcinoma without clinical features. Int $J$ Radiat Oncol. 2012;82(1):334-340. doi:10.1016/j. ijrobp.2010.09.040

20. Bacanli A, Ciftcioglu MA, Savas B, Alpsoy E. Nevoid basal cell carcinoma syndrome associated with unilateral renal agenesis: acceleration of basal cell carcinomas following radiotherapy. $J$ Eur Acad Dermatol Venereol. 2005;19(4):510-511. doi:10.1111/j.1468-3083.20 04.01169.x

21. Hölscher T, Bentzen SM, Baumann M. Influence of connective tissue diseases on the expression of radiation side effects: a systematic review. Radiother Oncol. 2006;78(2):123-130. doi:10.1016/j.radonc. 2005.12.013

22. Baker S, Joseph K, Tai P. Radiotherapy in Gorlin Syndrome: can it be safe and effective in adult patients? J Cutan Med Surg. 2016;20 (2):159-162. doi:10.1177/1203475415612481

23. Gold DG, Miller RC, Petersen IA, Osborn TG. Radiotherapy for malignancy in patients with scleroderma: the Mayo Clinic experience. Int J Radiat Oncol. 2007;67(2):559-567. doi:10.1016/j. ijrobp.2006.09.003

24. Bichakjian C, Armstrong A, Baum C, et al. Guidelines of care for the management of basal cell carcinoma. J Am Acad Dermatol. 2018;78 (3):540-559. doi:10.1016/j.jaad.2017.10.006

25. Joseph DL, Shumrick DL. Risks of head and neck surgery in previously irradiated patients. Arch Otolaryngol. 1973;97(5):381-384. doi:10.1001/archotol.1973.00780010393005

26. ScienceDirect. Cellular sources of transforming growth factor- $\beta$ isoforms in early and chronic radiation enteropathy. Available from: https://www-sciencedirect-com.ezp-prod1.hul.harvard.edu/science/ article/pii/S0002944010657410. Accessed December 1, 2021.

27. Johnson RL, Rothman AL, Xie J, et al. Human homolog of patched, a candidate gene for the basal cell nevus syndrome. Science. 1996;272(5268):1668-1671. doi:10.1126/science.272.5268.1668

28. Xie J, Murone M, Luoh SM, et al. Activating Smoothened mutations in sporadic basal-cell carcinoma. Nature. 1998;391(6662):90-92. doi: $10.1038 / 34201$

29. Aszterbaum M, Rothman A, Fisher M, et al. Identification of mutations in the human PATCHED gene in sporadic basal cell carcinomas and in patients with the basal cell nevus syndrome. J Invest Dermatol. 1998;110(6):885-888. doi:10.1046/j.1523-1747.1998.00222.x

30. Epstein EH. Basal cell carcinomas: attack of the hedgehog. Nat Rev Cancer. 2008;8(10):743-754. doi:10.1038/nrc2503

31. Genentech USA, Inc. Erivedge. U.S. Food and Drug Administration Website; 2012. Available from: https://www.accessdata.fda.gov/drug satfda_docs/label/2012/203388lbl.pdf. Accessed September 27, 2021.

32. Sun Pharmaceutical Industries, Inc. Odomozo. U.S. Food and Drug Administration Website; 2016. Available from: https://www.access data.fda.gov/drugsatfda_docs/label/2016/205266s002lbl.pdf. Accessed September 27, 2021.

33. Sekulic A, Migden MR, Basset-Seguin N, et al. Long-term safety and efficacy of vismodegib in patients with advanced basal cell carcinoma: final update of the pivotal ERIVANCE BCC study. BMC Cancer. 2017;17(1):1-10. doi:10.1186/s12885-017-3286-5 
34. Basset-Séguin N, Hauschild A, Kunstfeld R, et al. Vismodegib in patients with advanced basal cell carcinoma: primary analysis of STEVIE, an international, open-label trial. Eur J Cancer Oxf Engl. 2017;86:334-348. doi:10.1016/j.ejca.2017.08.022

35. Dummer R, Guminksi A, Gutzmer R, et al. Long-term efficacy and safety of sonidegib in patients with advanced basal cell carcinoma: 42-month analysis of the phase II randomized, double-blind BOLT study. Br J Dermatol. 2020;182(6):1369-1378. doi:10.1111/bjd. 18552

36. Xie P, Lefrançois P. Efficacy, safety, and comparison of sonic hedgehog inhibitors in basal cell carcinomas: a systematic review and meta-analysis. J Am Acad Dermatol. 2018;79(6):1089-1100.e17. doi:10.1016/j.jaad.2018.07.004

37. Bertrand N, Guerreschi P, Basset-Seguin N, et al. Vismodegib in neoadjuvant treatment of locally advanced basal cell carcinoma: first results of a multicenter, open-label, phase 2 trial (VISMONEO study): neoadjuvant vismodegib in locally advanced basal cell carcinoma. EClinicalMedicine. 2021;35:100844. doi:10.1016/j. eclinm.2021.100844

38. Kahana A, Unsworth SP, Andrews CA, et al. Vismodegib for preservation of visual function in patients with advanced periocular basal cell carcinoma: the VISORB trial. Oncologist. 2021;26(7): e1240-e1249. doi:10.1002/onco.13820

39. Lewis K, Dummer R, Farberg AS, Guminski A, Squittieri N, Migden M. Effects of sonidegib following dose reduction and treatment interruption in patients with advanced basal cell carcinoma during 42-month BOLT trial. Dermatol Ther. 2021;11 (6):2225-2234. doi:10.1007/s13555-021-00619-4

40. Chang ALS, Oro AE. Initial assessment of tumor regrowth after vismodegib in advanced basal cell carcinoma. Arch Dermatol. 2012;148(11):1324. doi:10.1001/archdermatol.2012.2354

41. Pricl S, Cortelazzi B, Dal Col V, et al. Smoothened (SMO) receptor mutations dictate resistance to vismodegib in basal cell carcinoma. Mol Oncol. 2015;9(2):389-397. doi:10.1016/j.molonc. 2014.09.003

42. Kim J, Aftab BT, Tang JY, et al. Itraconazole and arsenic trioxide inhibit hedgehog pathway activation and tumor growth associated with acquired resistance to smoothened antagonists. Cancer Cell. 2013;23(1):23-34. doi:10.1016/j.ccr.2012.11.017

43. Kim DJ, Kim J, Spaunhurst K, et al. Open-label, exploratory phase II trial of oral itraconazole for the treatment of basal cell carcinoma. J Clin Oncol. 2014;32(8):745-751. doi:10.1200/JCO.2013.49.9525

44. Ip KHK, McKerrow K. Itraconazole in the treatment of basal cell carcinoma: a case-based review of the literature. Australas J Dermatol. 2021;62(3):394-397. doi:10.1111/ajd.13655

45. Buchbinder EI, Desai A. CTLA-4 and PD-1 pathways. Am J Clin Oncol. 2016;39(1):98-106. doi:10.1097/COC.0000000000000239

46. Luke JJ, Ott PA. PD-1 pathway inhibitors: the next generation of immunotherapy for advanced melanoma. Oncotarget. 2015;6 (6):3479-3492. doi:10.18632/oncotarget.2980
47. Francisco LM, Salinas VH, Brown KE, et al. PD-L1 regulates the development, maintenance, and function of induced regulatory $\mathrm{T}$ cells. J Exp Med. 2009;206(13):3015-3029. doi:10.1084/jem.200 90847

48. Wang $\mathrm{C}$, Thudium KB, Han M, et al. In vitro characterization of the anti-PD-1 antibody nivolumab, BMS-936558, and in vivo toxicology in non-human primates. Cancer Immunol Res. 2014;2(9):846-856. doi:10.1158/2326-6066.CIR-14-0040

49. Zhao Y, Lee CK, Lin CH, et al. PD-L1:CD80 cis-heterodimer triggers the co-stimulatory receptor $\mathrm{CD} 28$ while repressing the inhibitory PD-1 and CTLA-4 pathways. Immunity. 2019;51(6):1059-1073.e9. doi:10.1016/j.immuni.2019.11.003

50. Chang J, Zhu GA, Cheung C, Li S, Kim J, Chang ALS. Association between programmed death ligand 1 expression in patients with basal cell carcinomas and the number of treatment modalities. JAMA Dermatol. 2017;153(4):285-290. doi:10.1001/jamadermatol.2016. 5062

51. Stratigos AJ, Sekulic A, Peris K, et al. Cemiplimab in locally advanced basal cell carcinoma after hedgehog inhibitor therapy: an open-label, multi-centre, single-arm, phase 2 trial. Lancet Oncol. 2021;22(6):848-857. doi:10.1016/S1470-2045(21)00126-1

52. Regeneron Pharmaceuticals, Inc. Libtayo. U.S. Food and Drug Administration Website; 2021. Available from: https://www.access data.fda.gov/drugsatfda_docs/label/2021/761097s007lbl.pdf. Accessed November 4, 2021.

53. Dumann K, Artz N, Ziemer M. Complete remission of basal cell carcinoma following treatment with cemiplimab after 2 years. JAMA Dermatol. 2021;157(8):1004. doi:10.1001/jamadermatol.2021.2206

54. Chang ALS, Tran DC, Cannon JGD, et al. Pembrolizumab for advanced basal cell carcinoma: an investigator-initiated, proof-ofconcept study. J Am Acad Dermatol. 2019;80(2):564-566. doi:10. 1016/j.jaad.2018.08.017

55. Ligtenberg KG, Hu JK, Damsky W, et al. Neoadjuvant anti-programmed cell death 1 therapy for locally advanced basal cell carcinoma in treatment-naive patients: a case series. JAAD Case Rep. 2020;6(7):628-633. doi:10.1016/j.jdcr.2020.05.010

56. Costa R, Carneiro BA, Agulnik M, et al. Toxicity profile of approved anti-PD-1 monoclonal antibodies in solid tumors: a systematic review and meta-analysis of randomized clinical trials. Oncotarget. 2016;8 (5):8910-8920. doi:10.18632/oncotarget.13315

57. Jacobsen AA, Aldahan AS, Hughes OB, Shah VV, Strasswimmer J. Hedgehog pathway inhibitor therapy for locally advanced and metastatic basal cell carcinoma: a systematic review and pooled analysis of interventional studies. JAMA Dermatol. 2016;152(7):816-824. doi:10.1001/jamadermatol.2016.0780

58. Velasco GD, Je Y, Bossé D, et al. Comprehensive meta-analysis of key immune-related adverse events from CTLA-4 and PD-1/PD-L1 inhibitors in cancer patients. Cancer Immunol Res. 2017;5(4): 312-318. doi:10.1158/2326-6066.CIR-16-0237

\section{Publish your work in this journal}

Drug Design, Development and Therapy is an international, peerreviewed open-access journal that spans the spectrum of drug design and development through to clinical applications. Clinical outcomes, patient safety, and programs for the development and effective, safe, and sustained use of medicines are a feature of the journal, which has also been accepted for indexing on PubMed Central. The manuscript management system is completely online and includes a very quick and fair peer-review system, which is all easy to use. Visit http://www. dovepress.com/testimonials.php to read real quotes from published authors. 